\title{
Analysis of Mortality Rates of the 5 Most Frequent Primary Cancer Sites in Brazil between 1979 and 2015 for Both Sexes
}

Luiz Carlos de Araújo Souza ${ }^{1}$, Hugo Oliveira de Figueiredo Cavalcanti ${ }^{2}$, Vinícius Carvalhêdo Cunha ${ }^{1}$ and Sandra Lúcia Branco Mendes Coutinho ${ }^{3}$

1. Undergraduates of Medicine in the University Center of Brasilia (UniCEUB) and Researchers in the Department of Cytopathology and Pathological Anatomy of the Base Institute of the Federal District (NUCAP-IHBDF), Hospital Medical Sector Sul- Asa Sul, Brasilia 70330-150, Brazil

2. Resident Physician in Anatomical Pathology of the Federal District Base Institute (NUCAP-IHBDF), Hospital Medical Sector SulAsa Sul, Brasilia 70330-150, Brazil

3. Physician Anatomopathologist and Head of the Department of Cytopathology and Anatomical Pathology of the Federal District Base Institute (NUCAP-IHBDF), Hospital Medical Sector Sul- Asa Sul, Brasilia 70330-150, Brazil

Highlights: Our work is a temporal analysis between 1979 and 2015 of the main neoplasia and death sites in Brazil. Thus, it has as principle the elaboration of descriptors and characteristics for determination and elucidation of this disease.

\begin{abstract}
Introduction: Global estimates determined that there would be 14.1 million new cases of cancer and 8.2 million deaths from cancer. Objectives: To determine the adjusted mortality rates of the 5 most frequent primary sites of cancer and the mortality rates of the 5 most frequent primary in Brazil, between 1979 and 2015. Method: Epidemiological study between 1979 and 2015 based on data obtained from the Online Atlas of Mortality provided by the National Cancer Institute of Brazil (INCA) using information on cancer deaths obtained within the System of Information on Mortality (SIM) of Brazil Ministry of Health. Results: When analyzing the mortality rate of the 5 most frequent primary sites by type of cancer from 1979 to 2015 for both sexes, we show that in the year 2015 the cancers with the highest rates are: bronchi and lungs, breast, stomach, prostate and unknown primary location. A total of 527,980 deaths from bronchial and lung neoplasms were recorded, 304,546 deaths from breast cancer were recorded, 407,611 deaths from stomach cancer were recorded, 268,061 deaths from prostate cancer were recorded, and 257,357 deaths due to neoplasia of unknown primary location were recorded. When we analyze the world standard rate and Brazil's standard rate for mortality, we show that Brazil has higher values for the 5 most frequent primary sites by type of cancer. Conclusion: The epidemiological study of these values aims to determine what are the main descriptors and characteristics to determine preventive measures against the increase of this disease.
\end{abstract}

Key words: Cancer, bronchi, breast, stomach, prostate, unknown primary location, Brazil, INCA.

\section{Introduction}

The main noncommunicable diseases (NCDs) are cardiovascular diseases, diabetes, cancers, chronic respiratory diseases, considered as rising, are responsible for the sickness and death of the world

Corresponding author: Luiz Carlos de Araújo Souza, Undergraduate of Medicine and Researcher in the Department of Cytopathology and Pathological Anatomy of the Base Institute of the Federal District (NUCAP-IHBDF). population [1]. The World Health Organization (WHO) estimated in 2012, with the exception of non-melanoma skin cancer, that there would be 14.1 million new cases of cancer and about 8.2 million deaths from cancer [2]. The analysis of global cancer prevalence in 2012 showed that 57\% (8 million) new cancers and 65\% (5.3 million) cancer deaths occurred in developing countries [2].

Males had higher rates of cancer incidence than 
females, and the highest incidence rates were observed in developed countries (Australia and New Zealand, North America, Western Europe and East Asia), with high rates of prostate cancer representing a significant driver at this elevation [2]. Mortality rates are higher in more developed regions than in less developed regions for both men (15\%) and women (8\%). Males have the highest mortality rates in Central and Eastern Europe and the lowest in West Africa. In contrast, the highest mortality rates in women are in Melanesia and East Africa, and the lowest in Central America and Central-South Asia [2].

Studies have found that in developed countries cancers are associated with urbanization and thus prevailing cancers of the lung, prostate, female breast, colon and rectum. However, in developing countries, cancers are associated with infections, with cancer of the cervix, stomach, esophagus and liver prevailing $[3,4]$.

This study aims to determine mortality rates of the 5 most frequent primary sites of cancer and to determine mortality rates of the 5 most frequent primary sites, crude and age-adjusted, by the world and Brazilian populations of 2010 per 100,000 men and women in Brazil, between 1979 and 2015.

\section{Materials and Methods}

Our work is an epidemiological study of a time series between 1979 and 2015 based on data obtained from the Online Atlas of Mortality provided by the National Cancer Institute of Brazil (INCA) using as source the System of Information on Mortality (SIM) of the Ministry of Health of Brazil, the information contained in the death declarations used the International Classification of Diseases (ICD) [5]. Information on death due to a certain type of cancer was organized by sex (male, female and total, in the option of total, deaths are considered for male, female and ignored); age group (available in the following categories: 0 to 4 ; 5 to $9 ; 10$ to 14 ; 15 to 19 ; 20 to 29 ;
30 to $39 ; 40$ to $49 ; 50$ to $59 ; 60$ to $69 ; 70$ to 79 ; 80 years or more, age ignored, and childhood -0 to 19 years); cause of death (malignant neoplasm according to the International Classification of Diseases-ICD).

Population estimates, both census (1991, 1996, 2000, 2010) and intercensitaries (1979 to 2012) used as denominators for calculating mortality rates, were obtained through Datasus and provided by the Brazilian Institute of Geography and Statistics $(\mathrm{IBGE})^{5}$. The world standard population used in this publication was the one proposed by Segi (1960), modified by Doll et al. (1966), and is also used in IARC's International Cancer Incidence in Five Continents series-CI5 publications [6-8]. This population was based on a combination of age structures of developed and developing countries.

Statistical methods took into account: percentage distribution-corresponds to the relative frequency of number of events (deaths) of a given topography in relation to the total number of cases; gross rate- the gross rate per 100,000 inhabitants refers to risk of occurrence of an event (deaths), is expressed as the quotient between the total number of events and population at risk; specific rate- the specific rate per 100,000 inhabitants refers to risk of occurrence of an event (deaths) due to a certain attribute (age, sex, marital status, socioeconomic level), is expressed as the quotient between the total of events by determined attribute and population at risk; age-adjusted rate-adjusting mortality rate allows to eliminate (or minimize) the effect of age differences between populations (or within the same population over different periods), so that geographical or temporal differences cannot be attributed to differences in age structure. Age adjustment, by direct method, is achieved using a single standard population, which works as a common weight group to calculate weighted rates (adjusted or standardized). Standard population used was the world population, previously described. 


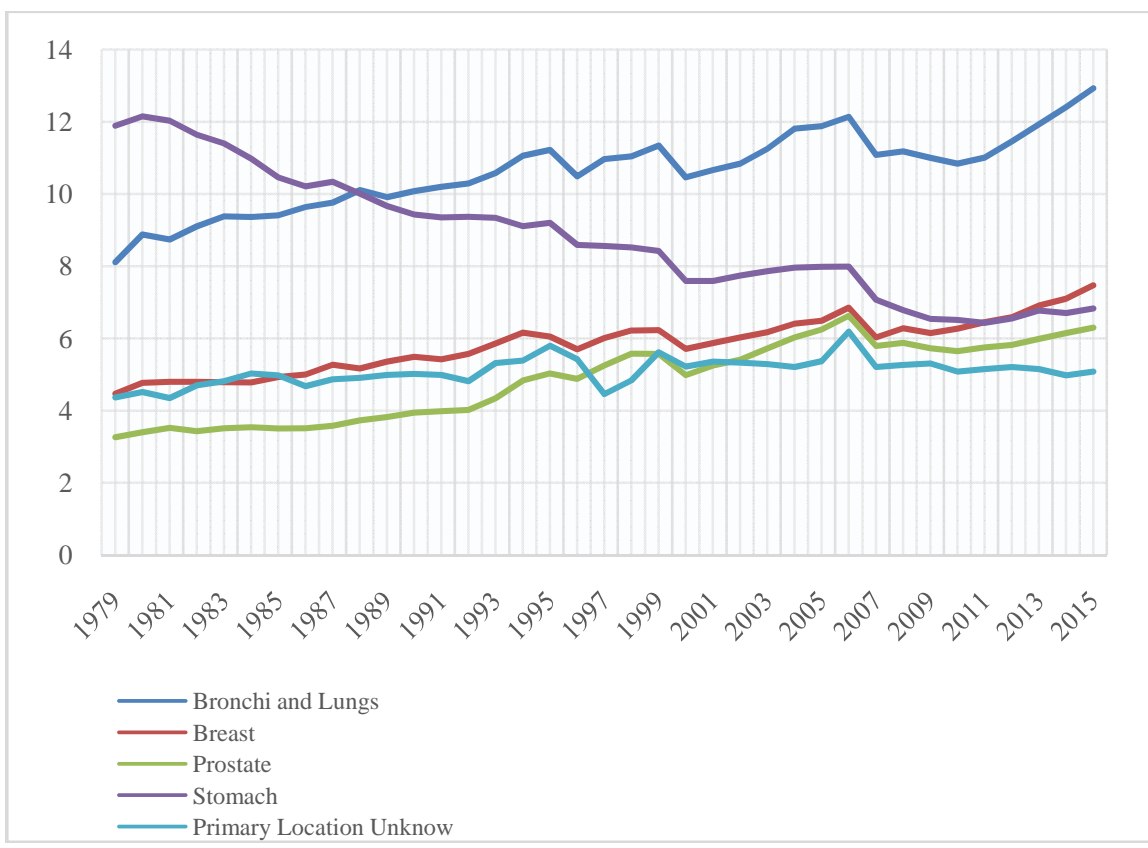

Fig. 1 Mortality rates of the 5 most frequent primary sites in 2015, adjusted for age, by the world population, per 100,000 men and women, Brazil, between 1979 and 2015. On vertical axis, adjusted rates are described, and on horizontal axis is described the years 1979 to 2015. Source: MS / SVS / DASIS / CGIAE / SIMMP / IBGE MS / INCA / Conprev / Surveillance Division [5].

\section{Results}

The analysis of the mortality rates of the 5 most frequent primary sites by type of cancer from 1979 to 2015 for both sexes, evidenced that stomach cancer mortality rates were initially higher in the 70s and 80 s in Brazil, but it declined and currently is the third highest rate (Fig. 1). Mortality rates for bronchial and lung cancers reached second place in the 1970s and 1980s, but have risen and have the highest rate. Mortality rates for breast cancers, prostate and unknown primary location have basically undergone few variations, however, breast cancer has outpaced mortality rates for stomach cancer and breast cancer has the second highest rate. Mortality rates for prostate cancer rose slightly, with the fourth highest rate, followed by rates of unknown primary localization cancers.

A total of 527,980 deaths from bronchial and lung neoplasms were recorded between 1979 and 2015, 356,288 (67.50\%) deaths were recorded for males and 171,517 (32.50\%) deaths for females (Table 1). When analyzing the age with the highest prevalence of bronchial and lung cancer deaths, we found that men between 60 and 69 years (32.16\%) are the most affected and women between 60 and 69 years (27.65\%) are the most affected compared with those for each sex. The comparison of the world and Brazilian population rates showed: gross rate for men of 12.18, world standard rate of 16.17, Brazil's standard rate of 16.94 and a gross rate for women of 5.69, world standard rate of 6.49, Brazilian standard rate of 6.87 .

A total of 304,546 deaths from breast cancer were recorded between 1979 and 2015, with 301,848 (99.11\%) deaths for females and 2,683 (0.89\%) deaths for males (Table 2). When analyzing the age with the highest prevalence of deaths in breast cancer, we show that women between 50 and 59 years (24.77\%) are the most affected and men between 60 and 69 years (25.12\%) are the most affected when comparing death by each sex. The comparison of the world and Brazilian population rates showed: gross rate for women of 10.02, world standard rate of 11.24, Brazil's standard rate of 12.04 and gross rate for men of 0.09 , world standard rate of 0.12 , Brazil's standard rate of 0.13 .

A total of 407,611 deaths from stomach cancer were 
Table 1 Mortality rates lung and bronchial cancer, gross and age-adjusted, by the world and Brazilian populations of 2010 per 100,000 men and women, Brazil, between 1979 and 2015. Source: MS / SVS / DASIS / CGIAE / SIMMP / IBGE MS / INCA / Conprev / Surveillance Division [5].

\begin{tabular}{lllllll}
\hline & \multicolumn{3}{c}{ Males } & \multicolumn{2}{c}{ Females } & \multicolumn{2}{c}{ All } \\
\cline { 2 - 7 } Age group (years) & Obito number & Specific fee & Obito number & Specific fee & Obito number & Specific fee \\
\hline 00 to 04 & 95 & 0.03 & 74 & 0.03 & 169 & 0.03 \\
05 to 09 & 57 & 0.02 & 65 & 0.02 & 123 & 0.02 \\
10 to 14 & 122 & 0.04 & 99 & 0.03 & 221 & 0.04 \\
15 to 19 & 380 & 0.13 & 248 & 0.08 & 629 & 0.1 \\
20 to 29 & 1,472 & 0.28 & 1,010 & 0.19 & 2,483 & 0.23 \\
30 to 39 & 4,797 & 1.15 & 3,892 & 0.89 & 8,693 & 1.02 \\
40 to 49 & 23,542 & 7.47 & 15,035 & 4.53 & 38,584 & 5.96 \\
50 to 59 & 71,275 & 33.36 & 34,955 & 15.15 & 106,263 & 23.91 \\
60 to 69 & 114,599 & 85.83 & 47,425 & 31.26 & 162,080 & 56.82 \\
70 to 79 & 99,720 & 147.44 & 43,563 & 52.11 & 143,321 & 94.77 \\
80 or more & 39,653 & 163.8 & 24,930 & 68.27 & 64,599 & 106.38 \\
Age ignored & 576 & 33.92 & 221 & 12.75 & 815 & 23.75 \\
All & 356,288 & - & 171,517 & - & 527,980 & - \\
Gross rate & - & 12.18 & - & 5.69 & - & 8.89 \\
World standard rate & - & 16.17 & - & 6.49 & - & 10.93 \\
Brazil standard rate & - & 16.94 & - & 6.87 & - & 11.45 \\
\hline
\end{tabular}

Table 2 Breast cancer mortality rates, gross and adjusted by age, by world and Brazilian populations of 2010, per 100,000 men and women in Brazil, between 1979 and 2015. Source: MS / SVS / DASIS / CGIAE / SIMMP / IBGE MS / INCA / Conprev / Surveillance Division [5].

\begin{tabular}{|c|c|c|c|c|c|c|}
\hline \multirow[b]{2}{*}{ Age group (years) } & \multicolumn{2}{|c|}{ Males } & \multicolumn{2}{|c|}{ Females } & \multicolumn{2}{|c|}{ All } \\
\hline & Obito number & Specific fee & Obito number & Specific fee & Obito number & Specific fee \\
\hline 00 to 04 & 0 & 0 & 10 & 0 & 10 & 0 \\
\hline 05 to 09 & 1 & 0 & 1 & 0 & 2 & 0 \\
\hline 10 to 14 & 1 & 0 & 15 & 0 & 16 & 0 \\
\hline 15 to 19 & 0 & 0 & 70 & 0.02 & 70 & 0.01 \\
\hline 20 to 29 & 22 & 0 & 2,746 & 0.51 & 2,768 & 0.26 \\
\hline 30 to 39 & 93 & 0.02 & 22,607 & 5.18 & 22,702 & 2.66 \\
\hline 40 to 49 & 273 & 0.09 & 56,383 & 16.99 & 56,657 & 8.76 \\
\hline 50 to 59 & 524 & 0.25 & 74,796 & 32.42 & 75,324 & 16.95 \\
\hline 60 to 69 & 674 & 0.5 & 64,295 & 42.38 & 64,969 & 22.78 \\
\hline 70 to 79 & 628 & 0.93 & 47,639 & 56.98 & 48,271 & 31.92 \\
\hline 80 or more & 464 & 1.92 & 32,951 & 90.23 & 33,418 & 55.03 \\
\hline Age ignored & 3 & 0.18 & 335 & 19.33 & 339 & 9.88 \\
\hline All & 2,683 & - & 301,848 & - & 304,546 & - \\
\hline Gross rate & - & 0.09 & - & 10.02 & - & 5.13 \\
\hline World standard rate & - & 0.12 & - & 11.24 & - & 6.04 \\
\hline Brazil standard rate & - & 0.13 & - & 12.04 & - & 6.5 \\
\hline
\end{tabular}

recorded between 1979 and 2015, 267,942 (65.75\%) deaths for males and 139.501 (34.25\%) deaths for females were recorded (Table 3). When analyzing the age with the highest prevalence of deaths in stomach cancer, we found that men between 60 and 69 years
(28.55\%) are the most affected and women between 70 and 79 years $(26.82 \%)$ are the most affected when comparing death by each sex. Comparison of the world and Brazilian population rates showed: gross rate for men of 9.16, world standard rate of 11.97, Brazil's 
standard rate of 12.77 and the gross rate for women of 4.63, world standard rate of 5.09, Brazil's default rate of 5.58 .

A total of 268,061 (100\%) deaths from prostate neoplasia were recorded between 1979 and 2015 (Table 4). When analyzing the age with the highest prevalence of deaths in prostate cancer, we showed that men between 70 and 79 years (37.55\%) are the most affected. Comparison of world and Brazilian population rates showed: gross rate for men of 9.16, world standard rate of 11.94, Brazil's standard rate of 14.25 .

Table 3 Mortality rates for stomach cancer, gross and adjusted by age, by the world and Brazilian populations of 2010, per 100,000 men and women, Brazil, between 1979 and 2015. Source: MS / SVS / DASIS / CGIAE / SIMMP / IBGE MS / INCA / Conprev / Surveillance Division [5].

\begin{tabular}{|c|c|c|c|c|c|c|}
\hline \multirow[b]{2}{*}{ Age group (years) } & \multicolumn{2}{|c|}{ Males } & \multicolumn{2}{|c|}{ Females } & \multicolumn{2}{|c|}{ All } \\
\hline & Obito number & Specific fee & Obito number & Specific fee & Obito number & Specific fee \\
\hline 00 to 04 & 34 & 0.01 & 23 & 0.01 & 57 & 0.01 \\
\hline 05 to 09 & 16 & 0.01 & 6 & 0 & 22 & 0 \\
\hline 10 to 14 & 37 & 0.01 & 39 & 0.01 & 76 & 0.01 \\
\hline 15 to 19 & 154 & 0.05 & 135 & 0.04 & 289 & 0.05 \\
\hline 20 to 29 & 1,523 & 0.29 & 1,667 & 0.31 & 3,192 & 0.3 \\
\hline 30 to 39 & 7,118 & 1.71 & 5,972 & 1.37 & 13,092 & 1.53 \\
\hline 40 to 49 & 23,604 & 7.49 & 12,587 & 3.79 & 36,205 & 5.6 \\
\hline 50 to 59 & 51,983 & 24.33 & 21,073 & 9.13 & 73,082 & 16.45 \\
\hline 60 to 69 & 76,493 & 57.29 & 31,715 & 20.9 & 108,255 & 37.95 \\
\hline 70 to 79 & 71,749 & 106.08 & 37,420 & 44.76 & 109,214 & 72.21 \\
\hline 80 or more & 34,659 & 143.17 & 28,557 & 78.2 & 63,229 & 104.12 \\
\hline Age ignored & 572 & 33.68 & 307 & 17.72 & 898 & 26.17 \\
\hline All & 267,942 & - & 139,501 & - & 407,611 & - \\
\hline Gross rate & - & 9.16 & - & 4.63 & - & 6.86 \\
\hline World standard rate & - & 11.97 & - & 5.09 & - & 8.26 \\
\hline Brazil standard rate & - & 12.77 & - & 5.58 & - & 8.86 \\
\hline
\end{tabular}

Table 4 Mortality rates for prostate cancer, gross and adjusted by age, by the world and Brazilian populations of 2010, per 100,000 men and women, Brazil, between 1979 and 2015. Source: MS / SVS / DASIS / CGIAE / SIMMP / IBGE MS / INCA / Conprev / Surveillance Division [5].

\begin{tabular}{|c|c|c|c|c|c|c|}
\hline \multirow[b]{2}{*}{ Age group (years) } & \multicolumn{2}{|c|}{ Males } & \multicolumn{2}{|c|}{ Females } & \multicolumn{2}{|c|}{ All } \\
\hline & Obito number & Specific fee & Obito number & Specific fee & Obito number & Specific fee \\
\hline 00 to 04 & 20 & 0.01 & 0 & 0 & 20 & 0 \\
\hline 05 to 09 & 5 & 0 & 0 & 0 & 5 & 0 \\
\hline 10 to 14 & 18 & 0.01 & 0 & 0 & 18 & 0 \\
\hline 15 to 19 & 66 & 0.02 & 0 & 0 & 66 & 0.01 \\
\hline 20 to 29 & 135 & 0.03 & 0 & 0 & 135 & 0.01 \\
\hline 30 to 39 & 294 & 0.07 & 0 & 0 & 294 & 0.03 \\
\hline 40 to 49 & 1,872 & 0.59 & 0 & 0 & 1,872 & 0.29 \\
\hline 50 to 59 & 13,475 & 6.31 & 0 & 0 & 13,475 & 3.03 \\
\hline 60 to 69 & 51,902 & 38.87 & 0 & 0 & 51,902 & 18.2 \\
\hline 70 to 79 & 100,669 & 148.84 & 0 & 0 & 100,670 & 66.56 \\
\hline 80 or more & 99,290 & 410.16 & 0 & 0 & 99,291 & 163.51 \\
\hline Age ignored & 312 & 18.37 & 0 & 0 & 313 & 9.12 \\
\hline All & 268,058 & - & 0 & - & 268,061 & - \\
\hline Gross rate & - & 9.16 & - & 0 & - & 4.51 \\
\hline World standard rate & - & 11.94 & - & 0 & - & 5.22 \\
\hline Brazil standard rate & - & 14.25 & - & 0 & - & 6.14 \\
\hline
\end{tabular}


Table 5 Mortality rates for neoplasia of unknown primary location, gross and adjusted by age, by the world and Brazilian populations of 2010, per 100,000 men and women, Brazil, between 1979 and 2015. Source: MS / SVS / DASIS / CGIAE / SIMMP / IBGE MS / INCA / Conprev / Surveillance Division [5].

\begin{tabular}{lllllll}
\hline & \multicolumn{3}{c}{ Males } & \multicolumn{3}{c}{ Females } \\
\cline { 2 - 7 } Age group (years) & Obito number & Specific fee & Obito number & Specific fee & Obito number & Specific fee \\
\hline 00 to 04 & 451 & 0.15 & 446 & 0.15 & 898 & 0.15 \\
05 to 09 & 311 & 0.1 & 241 & 0.08 & 554 & 0.09 \\
10 to 14 & 367 & 0.12 & 341 & 0.11 & 709 & 0.11 \\
15 to 19 & 828 & 0.28 & 655 & 0.22 & 1,483 & 0.25 \\
20 to 29 & 2,320 & 0.44 & 2,077 & 0.39 & 4,400 & 0.42 \\
30 to 39 & 4,304 & 1.03 & 5,554 & 1.27 & 9,865 & 1.16 \\
40 to 49 & 11,747 & 3.73 & 13,071 & 3.94 & 24,832 & 3.84 \\
50 to 59 & 25,234 & 11.81 & 22,900 & 9.93 & 48,152 & 10.84 \\
60 to 69 & 34,437 & 25.79 & 29,311 & 19.32 & 63,779 & 22.36 \\
70 to 79 & 32,362 & 47.85 & 29,483 & 35.27 & 61,865 & 40.91 \\
80 or more & 18,566 & 76.69 & 21,697 & 59.41 & 40,281 & 66.33 \\
Age ignored & 282 & 16.61 & 250 & 14.43 & 539 & 15.71 \\
All & 131,209 & - & 126,026 & - & 257,357 & - \\
Gross rate & - & 4.48 & - & 4.18 & - & 4.33 \\
World standard rate & - & 5.78 & - & 4.64 & - & 5.16 \\
Brazil standard rate & - & 6.22 & - & 5.01 & - & 5.55 \\
\hline
\end{tabular}

A total of 257,357 deaths due to neoplasia of unknown primary location were recorded between 1979 and 2015, 131,209 (51.01\%) deaths for males and 126,026 (48.99\%) deaths for females were recorded (Table 5). When analyzing the age with the highest prevalence of cancer deaths in unknown primary location, we found that men between 60 and 69 years (26.24\%) are the most affected and women between 70 and 79 years $(23.39 \%)$ are the most affected when comparing death by each sex. Comparison of world and Brazilian population rates showed: gross rate for men of 4.48, world standard rate of 5.78, Brazil's standard rate of 6.22 and the crude rate for women of 4.18, world standard rate of 4.64, Brazil's standard rate of 5.01 .

\section{Discussion}

Analysis of the most incidental cancers in the world has determined that lung, breast, intestine and prostate cancer are the most prevalent. A comparison of the most prevalent types of cancer in the world by sex determined that the most prevalent among men were lung (16.7\%), prostate (15.0\%), intestine (10.0\%), stomach (8.5\%) and liver (7.5\%), and among women the most prevalent were breast (25.2\%), intestine (9.2\%), lung (8.7\%), cervix (7.9\%) and liver (7.5\%) and stomach $(4.8 \%)[3,4]$.

In 2012, data from the latest worldwide estimate of lung cancer incidence showed that 1.8 million people will be diagnosed (12.9\% of all new cancers) and 1.6 million (19, 4\%) of deaths [3, 9]. Between 1979 and 2015, approximately 527,980 deaths from bronchial and lung neoplasms were recorded, 356,288 (67.50\%) deaths for males and 171,517 (32.50\%) deaths for females, males (32.16\%) and women (27.65\%) between the ages of 60 and 69 have the highest prevalence of deaths and Brazil's standard rate is higher than the world standard rate (Table 1).

Breast cancer represents the most prevalent neoplasm among women, excluding non-melanoma skin tumors. In the year 2012, global estimates determined that 1.67 million breast cancer would be diagnosed, about $25.2 \%$ of female malignancies, and breast cancer would be the leading cause of death for women with 522,000 deaths, about $14.7 \%$ of all female deaths [3, 10]. Between 1979 and 2015, 304,546 deaths from breast cancer were recorded, 301,848 (99.11\%) deaths for females and 2,683 (0.89\%) deaths for males, 
women (24.77\%) among 50 and 59 years old and men (25.12\%) between 60 and 69 years old have the highest prevalence of deaths and Brazil's standard rate is higher than the world standard rate (Table 2).

Stomach cancer ranks fifth in all cancers with the highest incidence in the world for 2012, reaching a prevalence of one million cases ( $6.8 \%$ of the total) [3]. There are significant differences in relation to the sex of greatest involvement, male sex is twice more affected than female sex, representing $8.5 \%$ of total cancers in men [10]. Stomach cancer is the third leading cause of death for both sexes worldwide, approximately 723,000 deaths ( $8.8 \%$ of the total) $[3,10$, 11]. Between 1979 and 2015, about 407,611 deaths from stomach cancer were recorded, 267,942 (65.75\%) deaths for males and 139.501 (34.25\%) deaths for females, males (28.55\%) among 60 and 69 years and women (26.82\%) between the ages of 70 and 79 have the highest prevalence of deaths and Brazil's standard rate is higher than the world standard rate (Table 3).

In a worldwide analysis, prostate cancer was considered the second malignant neoplasm that affects men, only lower than lung cancer [10]. The world estimates for 2012 revealed that 1.1 million men will be diagnosed with prostate cancer, representing $15 \%$ of all cancers for men [3, 10, 11]. In 2012, global estimates of male mortality from prostate cancer were around 307,000 deaths, about $6.6 \%$ of all male deaths [3, 10 , 11]. Mortality rate for prostate cancer has been higher in low-income countries when compared with high-income countries [12]. Between 1979 and 2015, approximately 268,061 deaths from prostate cancer were recorded; men (37.55\%) between the ages of 70 and 79 have the highest prevalence of deaths, and Brazil's standard rate is higher than the world standard rate (Table 4).

Cancer of Unknown Primary Site (CUP) is established when there is a histologically confirmed metastasis with absence of identifiable primary tumor [13]. In 2011, estimates determined that CUP represents the twelfth most common cancer, affecting 1 in 68 people of 85 years old [14]. Mortality rates have been decreasing over the years, although it still keeps high rates and poor prognosis [14]. Between 1979 and 2015, approximately 257,357 deaths from neoplasia of unknown primary location were recorded, 131,209 (51.01\%) deaths for males and 126,026 (48.99\%) deaths for females, males (26.24\%) between 60 and 69 years old and women (23.39\%) between the ages of 70 and 79 have the highest prevalence of deaths and Brazil's standard rate is higher than the world standard rate (Table 5).

\section{Conclusions}

Cancer in general terms is considered a non-transmissible disease that has shown increase in incidence and mortality rates worldwide. Epidemiological study of this abnormality aims to determine the main types of cancers, most affected sex, age group with the highest prevalence, standard rates of the respective country of study and the world to determine preventive measures against increase of this disease.

\section{Source of Financing}

The author(s) received no financial support for the research, authorship, and/or publication of this article.

\section{Conflict of Interests}

The author(s) declared no potential conflicts of interest with respect to the research, authorship, and/or publication of this article.

\section{References}

[1] Ullrich, A., and Miller, A. 2014. Global Response to the Burden of Cancer: The WHO Approach. Am Soc Clin Oncol Educ Book.

[2] World Health Organization. 2015. All Cancers (Excluding Non-melanoma Skin Cancer), Estimated Incidence, Mortality and Prevalence Worldwide in 2012. Lion: IARC. Available at: $<$ http://globocan.iarc.fr/Pages/fact_sheets_cancer. aspx>. Accessed on: September 11, 2017.

[3] Ferlay, J. et al. 2013. GLOBOCAN 2012 v1.0, Cancer Incidence and Mortality Worldwide. Lyon, France: IARC. 
(IARC CancerBase, 11). Available at: $<$ http://globocan.iarc.fr>. Accessed on: September 11, 2018.

[4] Estimate 2018: Incidence of Cancer in Brazil / National Cancer Institute José Alencar Gomes da Silva. 2017. Coordination of Prevention and Surveillance. Rio de Janeiro: INCA.

[5] MS (Ministry of Health of Brazil)/ SVS (Secretariat of Health Surveillance of Brazil)/ DASIS (Directorate of Administrative Support to the Health System of Brazil)/ CGIAE (General Coordination of Information and Epidemiological Analysis of Brazil)/ SIM (Brazilian Mortality Information System)/ IBGE (Brazilian Institute of Geography and Statistics Foundation)/ INCA (National Cancer Institute of Brazil)/ CONPREV (Coordination of Prevention and Surveillance of Brazil)/ Brazil Surveillance Division. Available at: $<$ https://mortalidade.inca.gov.br/MortalidadeWeb>. Accessed on: September 11, 2018.

[6] Segi, M. 1960. "Cancer Mortality for Selected Sites in 24 Countries (1950-57).” Department of Public Health, Tohoku University of Medicine, Sendai, Japan.

[7] Doll, R., Payne, P., Waterhouse, J. A. H., eds., 1966. Cancer Incidence in Five Continents (Vol. I). Union Internationale Contre le Cancer, Geneva.
[8] International Cancer Incidence in Five Continents-CI5 (Cancer Incidence in Five Continents, IARC). Available at: $<$ http://www-dep.iarc.fr/WHOdb/glossary.htm>. Accessed on: September 11, 2018.

[9] World Health Organization. 2015. GLOBOCAN 2012: Estimated Cancer Incidence, Mortality and Prevalence Worldwide in 2012. Lion: IARC. Available at: $<$ http://globocan.iarc.fr/Pages/fact_sheets_cancer. aspx> . Accessed on: September 11, 2018.

[10] Stewart, B. W., and Wild, C. P. ed., 2014. World Cancer Report: 2014. Lyon: IARC.

[11] Ferlay, J. et al. 2015. “Cancer Incidence and Mortality Worldwide: Sources, Methods and Major Patterns in GLOBOCAN 2012.” International Journal of Cancer 136 (5): 359-86.

[12] Nakandi, H. et al. 2013. "Knowledge, Attitudes and Practices of Ugandan Men Regarding Prostate Cancer." African Journal of Urology 19 (4): 165-70.

[13] Pentheroudakis, G., Briasoulis, E., and Pavlidis, N. 2007. "Cancer of unknown primary site: missing primary or missing biology?” Oncologist 12 (4): 418-25.

[14] Australian Institute of Health and Welfare. 2014. Cancer in Australia. An Overview 2014. Cancer series No. 90. Cat. no. CAN 88. Canberra: AIHW. 